\title{
СОЦИОЛОГИЯ
}

DOI: 10.17805/ggz.2018.2.5

\section{К интерпретации понятия «коррупция»: социетальные и социально-психологические аспекты}

С. Г. Карепова, С. В. Некрасов, А. Н. Пинчук

Институт сочиально-политических исследований РАН, г. Москва

В статье рассматривается коррупиия как сложноорганизованное, разноаспектное, латентное явление. Анализируются особенности коррупции как сочиетального феномена в рамках политико-правового, сочиальноэкономического и социокультурного подходов, осмысливается их сочетание в едином контенте. С опорой на концептуальные идеи психологии особое внимание уделяется субъекту коррупиии, который в данном случае становится носителем уникальных социально-психологических черт. В контексте анализа сочиетальных и сочиально-психологических аспектов феномена коррупции разрабатывается авторское определение понятия «коррупщия», позволяющее изучить его как комплексное явление.

Ключевые слова: коррупиия; сочиетальный аспект; социальнопсихологический аспект; субъекты коррупии

\section{On the Interpretation of the Concept "Corruption": Societal and Socio-psychological Aspects \\ S. G. Karepova, S. V. Nekrasov, A. N. Pinchuk Institute of Socio-Political Research, Russian Academy of Sciences, Moscow}

The article considers corruption as a complex, multi-aspect, and latent phenomenon. The authors analyze the features of corruption within the framework of the political and legal, socio-economic and socio-cultural approaches, and comprehend their combination in a consistent content. Based on the conceptual ideas of psychology, a special attention is paid to the subject of corruption that in this case becomes a bearer of unique social and psychological features. Within the context of analyzing the societal and socio-psychological aspects of the phenomenon of corruption, the authors' definition of the concept "corruption" is developed, allowing to consider it as a complex phenomenon.

Keywords: corruption; societal aspect; socio-psychological aspect; subjects of corruption 


\section{ВВЕДЕНИЕ}

Феномен коррупции относится к тому типу социальных явлений, интерес к которому со временем не ослабевает, а границы изучения постоянно расширяются, привлекая все больше внимания как представителей научного сообщества, так и различных профессиональных групп. Устойчивый интерес к коррупции во многом объясняется сложностью изучения и борьбы с данным явлением, а также его достаточно высокой сопротивляемостью предпринимаемым антикоррупционным мерам. Так, согласно данным международной организации Transparency International, Россия сохраняет относительно стабильное положение в группе стран с высоким уровнем коррупции. Измерение уровня коррупции и ранжирование стран в международном рейтинге происходит на основе Индекса восприятия коррупции (ИВК, Corruption Perception Index), который, варьируясь от нуля до ста баллов, показывает соответственно диапазон от самого высокого до самого низкого уровня восприятия коррупции. В 2017 г. Россия набрала 29 баллов из 100 и заняла 135-е место из 180 стран. Обращает на себя внимание тот факт, что за последние три года место России в данном рейтинге не изменилось (Россия в Индексе ... , 2018: Электронный ресурс).

Достаточно высокий уровень коррупции в стране отмечают и сами россияне, о чем свидетельствуют данные всероссийского опроса ФОМ, проведенного в феврале 2018 г. на фоне всплеска общественного интереса к аресту по подозрению в коррупции высокопоставленных чиновников в Республике Дагестан. В ходе опроса большинство респондентов (75 \%) ответили, что в России высокий уровень коррупции, 17 \% - средний, 2 \% - низкий (Уровень коррупции ..., 2018: Электронный ресурс).

Значительно дифференцируется оценка населением динамики изменения уровня коррупции в России. В частности, по мнению 38 \% участников опроса, в настоящее время уровень коррупции в стране повышается, 35 \% не видят никаких изменений. Положительные сдвиги наблюдают 15 \% опрошенных, утверждая, что уровень коррупции снижается (там же).

Неоднозначно россияне оценивают и итоги борьбы с коррупцией, что показывают результаты социологического опроса, осуществленного ВЦИОМ в 2016 г. Согласно мнению около половины опрошенных (46 \%), государству удалось достичь определенных результатов в рамках антикоррупционной деятельности. Однако только $13 \%$ из них ответили, что в стране делается много для борьбы с коррупцией, 33 \% признали, что результаты борьбы с коррупцией есть, но они не слишком значительны. Противоположную позицию занимают $47 \%$ респондентов, которые считают, что реальных результатов нет (25 \%), либо происходит усиление коррупции (22 \%) (Улюкаев ..., , 2016: Электронный ресурс). 
В срезе приведенных данных становится очевидной не только актуальность проблемы коррупции на сегодняшний день, но и значимость дальнейшей деятельности по ее искоренению. Как заметил на одном из заседаний Совета по противодействию коррупции Президент РФ В. В. Путин, «работы здесь очень и очень много. И вопрос не в том, чтобы с сегодня на завтра добиться ярких каких-то побед на этом поприще - наверное, это сложная задача, может быть, даже труднодостижимая. Но если мы остановимся, будет хуже. Двигаться нужно только вперед» (Заседание Совета ... , 2016: Электронный ресурс). Следует заметить, что данное заседание состоялось в конце января 2016 г. и уже два месяца спустя был утвержден Указ Президента РФ от 1 апреля 2016 № 147 «О Национальном плане противодействия коррупции на 2016-2017 годы» (Указ ... , 2016: Электронный ресурс), что показывает твердую позицию власти в вопросах дальнейшей борьбы с коррупцией.

Таким образом, и государство, и общество признают необходимость противодействия и профилактики коррупции в современных условиях. Однако ослабить ее проблематично в силу специфики данного феномена. Ведь коррупция относится к сложноорганизованным, разноаспектным, но при этом преднамеренно скрываемым социальным явлениям.

Представляя общественно опасный феномен, коррупция возникает в социальных организациях, стабильное функционирование которых предполагает стандартизацию, официально закрепленные практики и прозрачную работу, но, артикулируя теневую сторону неформальных отношений, коррупция латентно существует в системе формально регулируемых взаимодействий, превращаясь в дисфункциональный элемент системы.

Дуализм проблемы заключается в том, что коррупция нередко совершается «законопослушными» гражданами, которые, безусловно, замалчивают свою причастность к преступным деяниям. В связи с этим тема коррупции часто воспринимается в контексте настороженности и социальной напряженности. Между тем, паразитируя на общественных институтах, сама коррупция приобрела институциональные черты. Ее развитие на институциональном уровне усиливает социально-негативные и деструктивные последствия, которые способны дестабилизировать функционирование тех социальных институтов, в рамках которых воспроизводятся коррупционные практики. Пропорционально развитию и распространению коррупции возрастает угроза общественному порядку и стабильности. В контексте данных рассуждений становится очевидным, что коррупция представляет серьезную проблему для общества, актуальную для изучения тему, но при этом латентный для непосредственного исследования феномен.

Стоит отметить, что, несмотря на сложность исследовательской задачи, к феномену коррупции обращалось немало российских и зарубежных авто- 
ров. В итоге, с одной стороны, появился значительный научный задел для анализа коррупции как социального явления, представленный богатым и достаточно обширным массивом научно-исследовательских материалов. С другой стороны, проявились неоднозначность интерпретаций и идейная дискретность в осмыслении сущности коррупции. В последнее время в научной литературе все чаще стали появляться публикации, в которых осуществляется обзор различных точек зрения на феномен коррупции и предлагается авторская трактовка (Нисневич, 2016; Квон, 2015). Тем не менее единой формулировки с учетом социально-психологических противоречий, опосредующих специфику коррупции, до сих пор не найдено. В поисках полноты определения коррупции предлагаем подойти к ее исследованию как к комплексному феномену, объединяя социетальные и социально-психологические аспекты в едином русле анализа.

\section{СОЦИЕТАЛЬНЫЕ И СОЦИАЛЬНО-ПСИХОЛОГИЧЕСКИЕ АСПЕКТЫ ОСМЫСЛЕНИЯ КОРРУПЦИИ}

Начнем с того, что феномен коррупции носит социетальный характер, опосредованный совокупностью экономических, политических, социокультурных факторов жизни социума. Концептуальное рассмотрение социетального аспекта коррупции исходит из утверждения, что коррупция относится к многосторонним, но целостным явлениям. Иными словами, раскрывая коррупцию на социетальном уровне, необходимо не только выявить ее сущностные признаки в рамках политико-правового, социально-экономического и социокультурного подходов, но и проследить взаимосвязь между ними, осмыслить их сочетание в едином явлении.

Политико-правовой аспект понимания коррупциии. Согласно наиболее распространенной точке зрения, проблема коррупции возникла во властных структурах, что отразилось в длительной традиции изучения данного феномена в политико-правовом аспекте. Поскольку юридическо-правовое определение коррупции служит основой правоприменительной деятельности и имеет практику реализации, следует процитировать законодательно-закрепленную формулировку в качестве отправной точки дальнейшего теоретического анализа. Итак, согласно ФЗ от 25 декабря 2008 г. № 273 «О противодействии коррупции», коррупция - это «злоупотребление служебным положением, дача взятки, получение взятки, злоупотребление полномочиями, коммерческий подкуп либо иное незаконное использование физическим лицом своего должностного положения вопреки законным интересам общества и государства в целях получения выгоды в виде денег, ценностей, иного имущества или услуг имущественного характера, иных имущественных прав для себя или для третьих лиц либо незаконное предоставление такой выгоды указан- 
ному лицу другими физическими лицами» (Федеральный закон ... : Электронный ресурс).

В нормативно-правовом поле обнаруживаем, что общим основанием для квалификации коррупционных деяний служит незаконное использование должностного положения в корыстных целях.

Близкое по смыслу определение термин «коррупция» получает в политическом дискурсе. Тесная связь коррупции и государственной власти привела к формированию понятия «политическая коррупция». Ю. А. Нисневич определяет политическую коррупцию как использование должностным лицом «служебного положения и статуса в системе государственной власти, статуса органа государственной власти, который он представляет, в целях противоправного извлечения личной и (или) групповой, в том числе и в пользу третьих лиц, политической выгоды (политического обогащения)» (Нисневич, 2012: Электронный ресурс).

Анализируя специфичные признаки политической коррупции, Д. А. Квон замечает, что действия политических коррупционеров могут быть разнонаправлены и продолжительны во времени. Это объясняется тем, что должностные лица, занимающие властные позиции, имеют обширный круг знакомств, соприкасаются с определенными зонами политического влияния, поэтому услуги, которые они оказывают, могут быть универсальными и относиться к различным областям социальной жизни. В то же время ученый акцентирует достаточно скрытый и инвариантный характер политической коррупции, что связано со сферой ее распространения в политических кругах достаточно высокого уровня, недоступных для повседневного опыта большинства граждан (Квон, 2015: 47).

По мнению Е. А. Лазарева, к коррупционным практикам в сфере политики следует относить не только «откаты», взятки, а также «захват государства» и «захват бизнеса». В первом случае предполагается влияние групп интересов на выработку траекторий государственной политики. «Захват бизнеса» происходит в том случае, если посредством административных механизмов устанавливается неформальный контроль государства над секторами экономики (Лазарев, 2011: 51).

Экономический аспект восприятия коррупции. Дополнительную коннотацию дефиниция коррупции получает в контексте экономических теорий. В рамках экономического подхода чаще всего акцентируется рациональная основа поведения индивида. В модели коррупционных отношений экономисты обычно выделяют «поручителя (принципала) — исполнителя (агента) опекаемого (клиента)». В данном случае коррупция представляет процесс, когда агент, используя управленческие возможности, предоставленные ему принципалом, совершает определенные действия в интересах клиента за воз- 
награждение (Барсукова, 2008: 37). В агентских отношениях рассматривают следующие признаки коррупционного поведения агента: нарушение контракта принципала, предательство интересов принципала, воровство ресурсов принципала (Сатаров, 2004: 63).

В экономической науке также используют теорию коррупции как статусной ренты. Приверженцы данной теории считают, что в условиях ограниченности ресурсов коррупция выступает способом извлечения непроизводительного дохода и оптимизации необходимых издержек за счет использования доступных ресурсов в целях реализации своих интересов (Епифанова, 2007; Глинкина, 2010).

Социиально-культурные характеристики коррупции. Особую содержательную наполненность феномен коррупции приобретает в спектре анализа социально-культурных характеристик. В частности, связывая коррупцию с культурой, Т. А. Нестик выделяет три подхода к определению сущности коррупции на основе ее культурной составляющей. В рамках первого подхода коррупция и есть культура, то есть совокупность определенных ценностей, норм, представлений, обычаев и т. д. Второй подход базируется на теории структурного функционализма Т. Парсонса и Р. Мертона. С этой точки зрения коррупция представляет временную дисфункцию в культуре, которая возникает в ситуации аномии. Третий подход, напротив, позволяет объяснять коррупцию не как временное, болезненное состояние, а как стабильнофункционирующий феномен, воспроизводимый традицией национальной культуры (Нестик, 2002). Следует заметить, что, рассматривая коррупцию в реалиях российской действительности, ученые нередко артикулируют ее «национальный» характер, связывая особенности проявления коррупции с исторически-сложившимися условиями, ценностями, традициями, обычаями, культурным архетипом и менталитетом народа (Сидоров, 2008; Журавлев, Соснин, 2013).

Однако, как заметил профессор Апостолис Папакостас, коррупцию нельзя рассматривать исключительно как культурный феномен: «В коррупции присутствуют культурные элементы, но они обычно соотносятся с тем, как разные типы социальных отношений определяются и классифицируются в различных культурах» (Папакостас, 2016: 140). Имеется в виду, что коррупция проявляется, прежде всего, в социальных отношениях, причем, основанных на взаимном доверии (там же). Поэтому сущностное понимание коррупции значительно углубляет социологический аспект изучения, который показывает основы социального взаимодействия субъектов коррупции.

В контексте социологической рефлексии рассматриваются коррупционные практики, институциональные характеристики коррупции, поведение субъектов коррупционного взаимодействия, социокультурные условия жиз- 
недеятельности общества, опосредующие развитие и изменение динамики коррупции и другое.

Анализируя социальный аспект коррупции, М. Ю. Попов пишет, что это «асоциальное явление в жизни общества, вызванное деформациями в его социально-экономическом и политическом развитии, вследствие которых индивидуальное и массовое сознание трансформируется от общечеловеческих норм и ценностей в сторону примитивизации духовных и материальных потребностей, жизненных стандартов...» (Попов, 2010: 25).

Примечательно то, что, представляя собой в целом асоциальное явление, коррупция наказуема в границах юридическо-правовых норм, но при этом на уровне повседневных практик и обыденного сознания является объектом одобрения. Речь идет о том, что различные коррупционные действия нередко получают оправдание в общественном мнении, тогда как в законодательно-правовом пространстве могут относиться к уголовно или административно наказуемым деяниям. Подчеркивая данную особенность, современные социологи указывают на искажение общественной морали в плоскости коррупционных взаимодействий (Папакостас, 2016; Барсукова, 2008).

Итак, следуя стратегии понимания коррупции на уровне социетальной системы общества, объединим рассмотренные выше признаки в едином контенте уникального и самостоятельного феномена.

С юридической и политической точки зрения коррупция представляет незаконное злоупотребление должностным положением, это действие, основанием для которого выступает занятие властных позиций. Поскольку коррупция не всегда возникает во властных структурах, в качестве ключевой характеристики отметим наличие формально-закрепленных должностных прав, которые могут быть использованы нелегитимным способом в решении конкретных задач.

Достаточно важной для рассмотрения коррупции является экономическая сторона, которая акцентирует незаконное сотрудничество на взаимовыгодных или на выгодных одной стороне условиях в контексте признания определенных рисков. Исходя из того, что коррупция основана на нелегальном использовании должностных полномочий для выполнения определенного вида услуг, коррупционные отношения можно поместить в плоскость взаимодействия «исполнитель - заказчик», где исполнитель, используя имеющиеся доступные ресурсы на основе неформальных договоренностей, выполняет незаконно оплачиваемые работы или оказывает услуги.

В социиальном контексте понимание коррупции сопряжено с акцентацией особых социальных отношений между двумя (иногда более) субъектами. Отметим, что к субъектам коррупционных отношений будем относить отдельное лицо или группу лиц («исполнитель»), занимающих социальную 
позицию, открывающую доступ к властным, управленческим, экономическим и иным ресурсам, которые в рамках формально делегированных полномочий могут использоваться в индивидуальных (или в групповых) целях и интересах. Коррупционные отношения также включают другую сторону, «заказчика» (индивид или социальная группа), который согласен посредством вознаграждения или оказания услуг решить свои проблемы, получить желаемое т. д.

«Питательной почвой» для укрепления и распространения коррупционных практик является культурная составляющая. Напомним, что, с одной стороны, коррупция включает существенную культурную компоненту и имеет свои неформальные нормы и правила, регулирующие поведение субъектов коррупции. С другой стороны, коррупция занимает определенную нишу в системе общекультурных ценностей, детерминирующих ее место в массовом сознании как негативный или позитивный феномен. Это важное условие развития теневых коррупционных отношений, которые занимают пограничную позицию между неформальной легитимацией и формальными правоприменительными нормами.

Рассматривая сущностные признаки коррупции, следует уточнить, что социетальный аспект отражает коррупцию в многомерном социальном пространстве, в котором переплетаются социокультурные, политические, социально-экономические условия жизни общества, создавая основу для формирования, развития, изменения и распространения явления коррупции. В этих условиях коррупция зарождается как системное и комплексное явление, приобретая свою специфику и свойства.

В то же время коррупция и есть социетальная многосторонняя проблема, которая опосредована рядом социальных противоречий и проникает в различные сферы жизни общества, по-разному проявляясь в здравоохранении, системе образования, органах государственной власти и т. д. Поэтому виды коррупции, субъекты, разновидности коррупционных действий, нормы и правила коррупционного поведения, их содержательные особенности как объективные показатели конкретизируются в зависимости от опосредующих их условий.

Особую значимость в рамках социетального подхода приобретают концептуальные разработки академика Г. В. Осипова, посвященные изучению социальной реальности: «В этой перспективе социальная реальность представляет собой объективированный результат субъективной деятельности человека» (Коррупция: социально-психологическое . . , 2015: 203). Социальная реальность формируется в контексте субъективно-объективных разнонаправленных, взаимообусловленных действий различных социальных групп и индивидов. Интериоризируя созданную таким образом социальную 
реальность, актор социальных действий вносит изменения в данную реальность через самодетерминируемые субъективные проявления внутреннего мира.

В контексте осмысления подобной взаимозависимости становится очевидной социально-психологическая детерминанта коррупции. Коррупция, как особый феномен, интериоризируется как часть социальной реальности, но проявляется через действия конкретного индивида или группы лиц.

Иными словами, в коррупционных отношениях участвуют не абстрактные акторы действий (исполнитель - заказчик), а реальные люди, обладающие уникальным набором социально-психологических черт. Соглашаются брать взятки или предлагают «благодарность» конкретные люди, имеющие свои склонности, установки, мотивы, суждения, личностные смыслы. Вместе с тем оправдывают или осуждают данные действия такие же люди со своим уникальным набором индивидуально-личностных характеристик. Таким образом, социально-психологическая составляющая важна при исследовании коррупции, если ее игнорировать, то анализ будет незавершенным. Как справедливо замечают А. Л. Журавлев и А. В. Юревич, «коррупцию не принято воспринимать как психологическую проблему. Но это неверно хотя бы потому, что в одних и тех же обстоятельствах одни люди берут взятки, а другие - нет, одни социально-психологические условия способствуют формированию “взяточных” отношений, другие — препятствуют» (Журавлев, Юревич, 2014: 64).

Таким образом, с учетом многоаспектности феномена коррупции есть основание дать содержательно полное определение.

Коррупциия - это социальные действия субъектов, взаимодействующих в рамках незаконных латентных отношений, направленных на получение определенных выгод посредством использования нелегитимным способом формально-закрепленных прав, полномочий, ресурсов должностного положения. Феномен коррупции содержит субъективно-объективные составляющие. В качестве субъективных составляющих выделяются мотивы, ценности, самоидентичность участников коррупционного взаимодействия, особенности восприятия коррупции и т. д. Объективные составляющие представлены объемом рынка коррупции, видами коррупционного поведения, размером взяток и т. д. Механизмом реализации коррупции являются взаимоотношения между ее субъектами, основанные на социокультурных нормах, правилах, ценностях поведения, получающих свою специфику в различных сферах жизнедеятельности общества. Общение между субъектами коррупционного взаимодействия детерминируется социально-психологическими особенностями индивидов (способы взаимодействия, выработка совместной стратегии поведе- 
ния, восприятие участников коррупционного взаимодействия друг друга и Т. д.).

Коррупция явление динамичное, имеет свою процессуальную сторону, включающую:

- ормирование взаимоотношений между субъектами коррупции;

- продолжительность развития коррупционного взаимодействия во времени;

- повторяемость, регулярность взаимодействия;

- увеличение числа участников и расширение теневой сети коррупционного взаимодействия; и т. д.

\section{ЗАКЛЮЧЕНИЕ}

В результате анализа социетальных и социально-психологических особенностей феномена коррупции можно сделать вывод, что это комплексное и системное на уровне социума явление, проявляющееся в многоаспектности социетальной системы общества. Это позволяет увидеть коррупцию как сложное многостороннее явление с разных ракурсов в зависимости от научно-исследовательских интересов. Создание завершенного и исчерпывающего определения коррупции - достаточно труднодостижимая задача, что объясняется подвижной динамикой развития современной реальности, включенных в нее человека и общества и, как следствие, изменчивостью в ее контексте самого феномена коррупции. Тем не менее выделить ключевые аспекты для адекватного понимания сущности изучаемого феномена вполне возможно в концептуальном междисциплинарном поле социально-гуманитарных наук.

Углубленное понимание сущности коррупции, причин ее возникновения, механизмов функционирования требует системного анализа как социально-экономических, политико-правовых, социокультурных условий жизни социума, так и социально-психологических особенностей людей. Именно в сплетении данных условий коррупция как специфичный, самостоятельный, социетальный феномен проявляет себя. Соединяя социальные действия, через которые реализуется коррупция, с условиями их осуществления в едином контексте, можно получить информацию об институциональных характеристиках коррупции, специфики ее распространения в различных социальных институтах, особенностях воспроизводства коррупционных практик в современном социальном пространстве.

Концептуально развернутое определение включает психологическую доминанту. Эвристический потенциал психологических теорий значительно расширяет понимание субъектов коррупции (исполнитель - заказчик), которые в данном случае становятся носителями уникальных социально- 
психологических черт. Раскрытие психологической подоплеки коррупции дает возможность выявить психологические факторы коррупционного поведения, особенности восприятия коррупции в массовом сознании, составить социально-психологический портрет коррупциогенной личности, ответить на ряд других важных вопросов. Собственно, теоретико-методологические разработки психологической науки позволят на основе междисциплинарных исследований составить целостное представление о коррупции как о социетальном и социально-психологическом комплексном явлении.

\section{СПИСОК ЛИТЕРАТУРЫ}

Барсукова, С. Ю. (2008) Коррупция: научные дебаты и российская реальность // Общественные науки и современность. № 5. С. 36-47.

Глинкина, С. П. (2010) Феномен коррупции: взгляд экономиста [Электронный ресурс] // Новая и новейшая история. № 4. C. 3-17. URL: http://hist. msu.ru/Journals/NNI/pdfs/Glinkina_2010.pdf [архивировано в WaybackMachine] (дата обращения: 15.03.2018).

Епифанова, Н. (2007) Исследование коррупции на основе методов экономической теории // Вопросы экономики. № 1. С. 33-44.

Журавлев, А. Л., Соснин, В. А. (2013) Феномен коррупции в России как социополитическая и психологическая проблема // Прикладная юридическая психология. № 2. С. 8-24.

Журавлев, А. Л., Юревич, А. В. (2014) Психологические факторы коррупции // Социологические исследования. № 7. С. 63-71.

Заседание Совета по противодействию коррупции (2016) [Электронный ресурс] // Официальный сайт Президента России. 26 января. URL: http://kremlin.ru/events/president/news/51207 [архивировано в WaybackMachine] (дата обращения: 14.03.2018).

Квон, Д. А. (2015) Политическая коррупция: понятие, цели, субъекты // Власть. № 7. С. 45-52.

Коррупция: социально-психологическое измерение (2015) / под ред. Г. В. Осипова. М. : ИСПИ РАН. 230 с.

Лазарев, Е. А. (2011) Коррупция и политическая стабильность: институциональная перспектива // Полития: Анализ. Хроника. Прогноз (Журнал политической философии и социологии политики). № 1 (60). С. 50-68.

Нестик, Т. А. (2002) Коррупция и культура // Экономическая теория преступлений и наказаний. Вып. 4: Теневая экономика в советском и постсоветском обществах. Ч. 2: Статьи. Библиография. С. 82-94.

Нисневич, Ю. А. (2012) Политическая коррупция: определение, формы проявления, механизмы и ресурсы [Электронный ресурс] // Технологизация политических процессов в условиях глобализации: теория, опыт, перспективы : материалы Международной научно-практической конференции, Москва 19 октября 2012 г. / под общ. ред. В. И. Камышанова, О. Е. Гришина. 308 с. C. 193-201. URL: https:/publications.hse.ru/mirror/pubs/share/folder/6lxafrpk03/ 
direct/63968530 [архивировано в WaybackMachine] (дата обращения: 15.03. 2018).

Нисневич, Ю. А. (2016) Коррупция: инструментальная концептуализация // Социологические исследования. № 5. С. 61-68.

Папакостас, А. (2016) Становление цивилизационной публичной сферы : недоверие, доверие и коррупция. М. : ВЦИОМ. 224 с.

Попов, М. Ю. (2010) Институты гражданского общества против коррупции // Историческая и социально-образовательная мысль. № 2. С. 24-31.

Россия в Индексе восприятия коррупции - 2017: посадки не помогли (2018) [Электронный ресурс] // Центр «Трансперенси Интернешнл-Р». 21 февраля. URL: https://transparency.org.ru/research/indeks-vospriyatiya-korruptsii/rossiya-v-indekse-vospriyatiya-korruptsii-2017-posadki-ne-pomogli.html [apхивировано в WaybackMachine] (дата обращения: 14.03.2018).

Сатаров, Г. Л. (2004) Коррупционные отношения: агентская модель и смежные подходы // Общественные науки и современность. № 2. С. 60-69.

Сидоров, А. И. (2008) Коррупция: и диагноз, и приговор // Социологические исследования. № 2. С. 111-117.

Указ Президента РФ от 1 апреля 2016 № 147 «О Национальном плане противодействия коррупции на 2016-2017 годы» [Электронный ресурс] // ГАРАНТ.РУ : Информационно-правовой портал. URL: http://garant.ru/products/ipo/prime/doc/71264578/ [архивировано в WaybackMachine] (дата обращения: 14.03.2018).

Улюкаев: один в поле? (2016) [Электронный ресурс] // ВЦИОМ. Прессвыпуск № 3251 от 25 ноября. URL: https://wciom.ru/index.php?id=236\& uid=115966 [архивировано в WaybackMachine] (дата обращения: 14.03.2018).

Уровень коррупции в России. События в Дагестане (2018) [Электронный ресурс] // ФОМ. 13 марта. URL: http://fom.ru/Bezopasnost-i-pravo/13984 [архивировано в WaybackMachine] (дата обращения: 14.03.2018).

Федеральный закон от 25 декабря 2008 г. № 273-Ф3 «О противодействии коррупции» (с изменениями и дополнениями) [Электронный ресурс] // Система «Гарант». URL: http://ivo.garant.ru/\#/document/12164203/paragraph/ 2769:0 (дата обращения: 14.03.2018).

Дата поступления: 16.03.2018 г.

Карепова Светлана Геннадьевна - кандидат социологических наук, ведущий научный сотрудник Института социально-политических исследований Российской академии наук. Адрес: 119333, Москва, ул. Фотиевой, д. 6, к. 1. Тел.: +7 (499) 530-28-84. Эл. адрес: Svetlran@mail.ru

Некрасов Сергей Владимирович - научный сотрудник Института социально-политических исследований Российской академии наук. Адрес: 119333, Москва, ул. Фотиевой, д. 6, к. 1. Тел.: +7 (499) 530-28-84. Эл. адрес: sv_79@inbox.ru 
Пинчук Антонина Николаевна - научный сотрудник Института социально-политических исследований Российской академии наук. Адрес: 119333, Москва, ул. Фотиевой, д. 6, к. 1. Тел.: +7 (499) 530-28-84. Эл. адрес: antonina.pinchuk27@bk.ru

Karepova Svetlana Gennadievna, Candidate of Sociology, Leading Researcher, Institute of Socio-Political Research, Russian Academy of Sciences. Postal address: Bldg. 1, 6 Fotievoi St., 119333 Moscow, Russian Federation. Tel.: +7 (499) 530-28-84. E-mail: Svetlran@mail.ru

Nekrasov Sergey Vladimirovich, Researcher, Institute of Socio-Political Research, Russian Academy of Sciences. Postal address: Bldg. 1, 6 Fotievoi St., 119333 Moscow, Russian Federation. Tel.: +7 (499) 530-28-84. E-mail: sv_79@inbox.ru

Pinchuk Antonina Nikolaevna, Researcher, Institute of Socio-Political Research, Russian Academy of Sciences. Postal address: Bldg. 1, 6 Fotievoi St., 119333 Moscow, Russian Federation. Tel.: +7 (499) 530-28-84. E-mail: antonina.pinchuk27@bk.ru

\section{Для ичитирования:}

Карепова С. Г., Некрасов С. В., Пинчук А. Н. К интерпретации понятия «коррупция»: социетальные и социально-психологические аспекты [Электронный ресурс] // Горизонты гуманитарного знания. 2018. № 2. С. 52-64. URL: http://journals.mosgu.ru/ggz/article/view/755 (дата обращения: дд.мм. гггг). DOI: 10.17805/ggz.2018.2.5 